\title{
Fostering RN-to-BSN Students' Confidence in Searching Online for Scholarly Information on Evidence-Based Practice
}

\author{
Carol McCulley \\ Linfield College \\ Melissa Jones \\ Linfield College - Adult Degree Program
}

Follow this and additional works at: https://digitalcommons.linfield.edu/librariesfac_pubs

Part of the Educational Methods Commons, Information Literacy Commons, and the Nursing Commons

\section{DigitalCommons@Linfield Citation}

McCulley, Carol and Jones, Melissa, "Fostering RN-to-BSN Students' Confidence in Searching Online for Scholarly Information on Evidence-Based Practice" (2014). Faculty \& Staff Publications. Accepted Version. Submission 10.

https://digitalcommons.linfield.edu/librariesfac_pubs/10

This Accepted Version is protected by copyright and/or related rights. It is brought to you for free via open access, courtesy of DigitalCommons@Linfield, with permission from the rights-holder(s). Your use of this Accepted Version must comply with the Terms of Use for material posted in DigitalCommons@Linfield, or with other stated terms (such as a Creative Commons license) indicated in the record and/or on the work itself. For more information, or if you have questions about permitted uses, please contact digitalcommons@linfield.edu. 


\begin{abstract}
Graduates of bachelor of science in nursing (BSN) programs and increasingly expected to take an active role in assessing and improving nursing practice and for nurse educators to prepare BSN students for this expanding role. Information literacy, the ability to search for, find, get, and use scholarly information to inform nursing practice should be a critical component of nursing education. This article focuses on five strategies for teaching information literacy to registered nurse (RN)-to-BSN students in an online continuing education environment. These strategies include the addition of an embedded librarian in the online courses, collaboration between librarian and nursing faculty, a subject guide with access to resources and tutorials at the point of need, student-centered learning with authentic assignments, and reflection on the learning process. Student reflections suggest that these strategies result in increased confidence in searching for and finding the evidence-based scholarship that they need.

Nurse educators are now being asked to integrate informatics, information technology, and information literacy into their already full curricula to prepare bachelor of science in nursing (BSN) graduates for an active role in assessing and improving nursing practice. This article describes a successful collaboration between a librarian and nursing faculty to incorporate information literacy into an online continuing education registered nurse (RN)-to-BSN program. The strategies described were based on the teaching experiences and expertise of the authors and the literature discussing changes in nursing education, information literacy instruction, and online education. Convenience was a primary consideration in course planning in order to respond to the searching habits of the students. Student reflections suggest that an early introduction to library resources and the search process with a librarian, reinforced by nursing faculty assignments, and continuous access to the librarian, can increase students' awareness of
\end{abstract}


resources and confidence in their ability to search for and find the evidence-based scholarship that they need to respond to the new expectations.

\section{LITERATURE REVIEW}

The Institute of Medicine (IOM) (2010) called for fundamental changes in nursing education and an increase in the number of BSN nurses from the current $50 \%$ to $80 \%$ of the workforce by 2020. Nursing care is shifting from acute to chronic care for an aging population. It also includes an increasing emphasis on community health and policy and will continue to operate in a highly technological environment. These changes call for a deeper understanding of the complexities of the practice of nursing, including evidence-based practice. BSNs have been introduced to a wider range of competencies to meet these challenges (Institute of Medicine, 2011). The Tri-Council of Nursing (American Association of Colleges of Nursing, 2012) also has called for major changes in nursing education and a requirement for nursing students and practicing nurses to earn, at a minimum, a BSN. Online RN-to-BSN continuing education programs have made BSN degrees possible for practicing RNs, many of whom have full time jobs and families or do not live near an academic institution that offers traditional programs.

Progress has been slow in incorporating information technology and information literacy into nursing curricula because there is no common understanding of the terms and they are often used interchangeably (Arguelles, 2012). Arguelles suggested that enhancements to information technology enhancements, such as electronic health records are more visible in the hospital environment, and as a result, information technology is often what is emphasized in nursing education. 
Confusion about information literacy also creates barriers to its inclusion in nursing curricula. Information literacy is defined as the ability to formulate questions, search for, find, evaluate, get, and use information responsibility (Association of College and Research Libraries, 2000). According to the American Association of the College of Nursing (2008), BSN graduates should be prepared to find and use evidence to inform their practice. Arguelles (2012) recommended collaboration between librarians and nurse educators to teach the process of information literacy to allow nurses to provide evidence for improving the safety and quality of patient care. Flood, Gasiewicz, and Delpier (2010) emphasized the need to integrate information literacy throughout the curriculum so that it can become part of nursing practice.

Convenience, in terms of access to and ease of use of resources and time, has a significant influence on where where people seek information (Connaway, Dickey, \& Radford, 2011; Solomons \& Spross, 2011). This makes using one's own experience, asking colleagues, and searching Google very convenient, but it can be a barrier to finding scholarly research. O'Keefe, Willinsky, and Maggio (2011) surveyed and interviewed health personnel, including nurses, in a community-based clinic and an independent teaching hospital. The authors found that of the personnel who consulted sources weekly, $83 \%$ relied on colleagues for information, $77 \%$ used collections of sources like the Cochrane Systematic Reviews, and 32\% used primary literature. Twenty-seven percent of the respondents used PubMed, but the most frequently used sources for health information were Google and Wikipedia. Slawson and Shaughnessy (2005) refer to the process of convenience research as "satisficing." Is the best literature being sacrificed for convenience?

Confidence is another barrier to successful searching for scholarly information. Pravikoff, Tanner, and Pierce (2005) surveyed 3,000 RNs in the United States to examine their perceptions 
of access to evidence-based research and their confidence in searching for this information. The 1,097 respondents indicated that, although they needed evidence-based research to inform their practice, they most often asked colleagues or peers or searched the Internet because they lacked the confidence and skills to search databases like PubMed or CINAHL and did not know how to access full text sources. Senior students in a BSN program who were seeking information for class assignments reported a lack of confidence in finding keywords that return a manageable number of relevant results, using the CINAHL database, or even that CINAHL would have information relevant to their topics (Duncan \& Holtslander, 2012).

Knowledge of PubMed with links to many open-access research articles including those published in the PubMed Central archive as a result of the National Institutes of Health mandate, would help address the perceived barrier to access. The National Science Foundation (2013) announced its intention to expand public access to the research it funds, which would make even more research articles freely available.

\section{TEACHING STRATEGIES}

\section{Embedded Librarians}

Sullo, Harrod, Butera, and Gomes (2012) are librarians embedded in Blackboard classes for students in the schools of Medicine, Nursing and the Health Sciences at The George Washington University. The authors based their instruction on the types of questions that had been asked of librarians and a series of best practices for online learning. The courses were designed to make students more comfortable contacting the librarian for help. Strategies included introduction by the nursing faculty teaching the course and a personal introduction from the librarian. Reeb and Gibbons (2004) found that a photo of the librarian in the guide increased student contacts. 
A survey of embedded librarians found that the most popular services used by students in online courses were links to library databases and other library services $(76 \%)$ and encouragement to contact the embedded librarian (76\%). Other popular approaches included having the same librarian embedded in more than one course (73\%), adding a library tab or link to the library website in each online course $(72 \%)$, providing tutorials that were linked in the course $(69 \%)$, and offering information on research concepts (66\%) (J. J. Burke, personal communication, January 8, 2011).

This article reports on the collaboration between a librarian and a nursing faculty in the first two classes of an online continuing education RN-to-BSN program. Students are introduced to the library resources early in the first course because the nurses begin to do research and write papers early in their program. The focus is on the RN to BSN nursing library research guide that contains specific resources including databases. In addition, the librarian's e-mail address is shown on each page, along with services, tips, and tutorials to make it convenient for the students to find what they need for their research. The librarian is embedded in the second course to be available for questions and to reinforce what the students learned in the first class and remind them of the research process and resources in their nursing library guide. An embedded librarian in an online course can be proactive posting tips or asking for questions as students begin their literature review and work through the research process. Suggestions or solicitations of questions are made in the discussion section of Blackboard to elicit a group discussion or to all students individually through e-mail. Getting an individual message makes it convenient for a student to reply with a question. Two students commented on the timing of the library assignment and the access to the librarian. One student remarked, "I feel more at ease about accessing information and that there is always someone I can ask whenever there is some 
confusion." The other noted, "I am extremely thankful we had this exercise now so that I can practice more before I need to use it to write a research paper."

\section{Collaboration}

Collaboration between librarians and nursing faculty in RN-to-BSN programs is recommended in order for students to develop the information literacy skills they need to do the research required as BSN nurses (Schutt \& Hightower, 2009). Collaboration takes advantage of the strengths of both disciplines to improve student outcomes for finding current scholarly evidence (Turnbull, Royal, \& Purnell, 2011), to establish a successful scaffolded program where information literacy outcomes are integrated into course learning outcomes (Kvenild \& Calkins, 2011), and to build student confidence in the outcomes of the search process (Arguelles, 2012). Miller, Jones, Graves, and Sievert (2010) reported that a collaboration between librarians and nurse educators based on a mutual understanding and incorporation of the relevant content of each discipline in nursing courses can build connections between nursing practice and the evidence on which it is based.

In a study by Schulte and Sherwill-Navarro (2009), 60\% of nursing faculty who completed the survey indicated that the need for evidence-based research as a basis for nursing practice had greatly or somewhat increased their desire to have librarians teach instructional sessions.

Collaboration with librarians on assessment and curriculum support rated even higher.

In the online RN-to-BSN continuing education program discussed in this article, collaboration makes the library research guide and tutorials more effective because they were understood and supported by the nursing faculty. The nursing faculty commented to the librarian, "In a post in the question area, I did remind students to contact you if they have research challenges. ... as a reminder that you are there and the expectation is that they are utilizing the 
library." The librarian also posted an introduction and had a link in the Blackboard discussion section for questions. When the librarian suggested an announcement to answer a question that she had been asked several times, a nurse faculty teaching an upper division course replied "I just posted the announcement and also advised them that you would be an excellent source for helping them find articles if needed for their evidence based project. Thanks again." Students see these collaborative efforts to facilitate learning.

As a result of the initial collaboration, the librarian was embedded in several upper division classes and the RN-to-BSN library research guide was linked in all nursing classes. In the future the collaboration will be more extensive to coordinate more intentional ways to integrate information literacy into upper-level courses. Continuous assessment of learning outcomes over more courses should improve teaching and student learning (Oakleaf, 2010).

\section{Subject Guides and Tutorials}

Course management systems allow links to research guides in the navigation bar of each course and therefore at the point of need for students. A link to the library homepage was too general for the navigation bar, but was included in the guide. Including links in the course guide offered students a convenient way to contact the librarian with additional questions. One student commented. "After enough frustration, I emailed our librarian. She almost immediately emailed me back and gave me some suggestions."

The online library research guide for this RN-to-BSN program makes it convenient to link to tips and tutorials that are available 24 hours a day. Currently, the same guide is in each class of the RN-to-BSN program because students use CINAHL, PubMed, and Google Scholar in all their classes during the 2-year program. Knowing how to search, evaluate sources, get full text and cite sources are as important for the first assignment as they are for the last. Student 
comments have supported the value of these tools. "There is a lot of help on our library page, with links to audio and written tutorials." Another said, "Oh how I have struggled with CINAHL over the years! Our librarian has done a great job with her library overview and tutorials." Another added, "With the videos and informative library access page on Blackboard, I am more capable navigating, researching, and utilizing the available resources." A new assignmentspecific library research guide also will be linked in one of the spring 2014 classes in response to the faculty-recognized need for more extensive research information for a multifaceted assignment.

Point-of-need tutorials within subject or course guides can help to develop nursing students' information literacy skills and answer frequently asked questions (Kimok \& Heller-Ross, 2008; Turnbull, Royal, \& Purnell, 2011). There are short tutorials in the RN-to-BSN research guide based on common questions such as, "I have found the perfect article, but I can only get the abstract. How can I get the full text?" The research guide included is a "getting full text" tab with links to the necessary resources as well as two short video screen capture (Jing) tutorials that were added in response to that question. Jing tutorials are easy to use and while the free Jing is limited to five minutes, that is adequate to explain one concept or answer one question. One student reflected on the short tutorials, saying, "I agree that the tutorials are invaluable. I found myself referring to them a few times and it was nice to have that quick 90 second, 'here's how you do it,' rather than a half-hour tutorial." The tutorials helped another student narrow her search results. She remarked, "After watching the tutorials, I got fewer results, but more relevant ones."

\section{Student-centered Learning Including Authentic (Real-Life) Assignments}


Essential III: Scholarship for Evidence Based Practice from The Essentials of Baccalaureate Education for Professional Nursing Practice states, "Professional nursing practice is grounded in the translation of current evidence in one's practice," (AACN, 2008, p. 3). Authentic (real-life) research assignments encourage student engagement in their learning. Authentic assignments, along with problem-based, student-centered learning and course-integrated library instruction, are used because of their positive effect on information literacy learning outcomes (Diekema, Holliday, \& Leary, 2011; Fox \& Doherty, 2012). Hickey, Forbes, and Greenfield (2010) recommended replacing teacher-centered pedagogy with innovative student-centered pedagogy to educate BSN students to be critical thinkers, problem solvers, prioritizers, communicators, and collaborators (p. 218), all skills necessary to find and use current evidence in the practice of nursing. These strategies form the basis of the online instruction to the RN-to-BSN students in this program.

Choosing an authentic research assignment question from the context of their work engages RNs with the iterative process of finding scholarly information they care about to learn something they want to know. They are not just doing an assignment, but learning how to be life-long learners. The iterative process in the library assignment in the first class of this program began with the development of a search strategy for the nurse-selected research question. Students were asked not only to write the main words and synonyms for those words in their research questions, but also to write what they already knew about their topic and what they want to know to immerse themselves in their research question. Students were encouraged to add words and add or change their, "what do you want to know" statements as they did their research. Students used combinations of their keywords to search CINAHL and PubMed and compare the results. They completed a chart with the search terms used, limits chosen (not full 
text), number of results, new keywords, subjects, or MESH terms discovered. One student's comment about this exercise was, "It was very helpful to think of what I already knew about my topic and possibly use synonyms to search for articles."

The next step in the assignment is to choose the most relevant and credible article they found and write a short (150-350 words) annotation for that article. The annotation should include: the citation information (APA style), the database in which the article was found, a summary of the article, why it is credible, and how it is relevant to their topic or how the information could be used. A descriptive grading rubric was posted with the assignment, so students were aware of the learning outcomes. The rubric described four levels of achievement for each of the six components of the assignment. The six components were the search strategy, the CINAHL/PubMed comparison chart, the APA citation, the article summary, evaluation of the source for credibility, and a statement of the relevancy of the information for the student. The rubrics not only provided the students with expectations for the assignment, but also made grading more consistent and less time consuming for the librarian (Suskie, 2010). For this assignment, students had a chance to resubmit their work after reviewing the librarian's comments and the graded rubric. It was important for students get the most out of the assignment at this stage because it provided the basis of the scaffolding for their future research.

\section{Reflection}

Reflection is an important part of learning (Ryan \& Ryan, 2013). This includes learning to become information literate. Writing a 1-minute reflection on a class exercise or keeping a journal for a longer-term assignment are both effective methods of engaging students in reflective learning (Duncan \& Holtslander, 2012; Suskie, 2010). 
During the library assignment week, small group discussions were held on Blackboard so that students could describe their search process and results using the information from their assignments and comment on each other's descriptions. This gave them a chance to compare experiences, learn from each other, and build community. Students have given each other insightful suggestions. One appreciative student posted, “If I hadn't read other posts including yours, I don't think I would have taken these search options into consideration for my future needs." The students also discussed the most important thing that they learned and the most confusing or frustrating thing that they experienced during the process. This not only gave students a chance to reflect on what they learned during their research process, but also provided a quick qualitative method for assessing what they learned from the assignment as well as a way to address problems before they undertook future assignments. One student commented, "The most important thing and the most confusing thing were the same really--I learned that I need to practice and get familiar with the databases. The whole process is confusing and overwhelming but the more I play with it the better I become and that's what is most important." Another said, "I struggled a lot at first with this assignment. When I finally 'got it' I felt a lot of personal satisfaction." Another student remarked, "The most important thing I learned was that I could actually find what I was looking for and that was amazing to me." Another commented, "This learning process was very time consuming, but I feel much more empowered now to seek out my own reliable information. As I looked at different articles and topics related to mine, I think it helped broaden my scope of thinking and started me to ask more questions."

Members of the spring $2013 \mathrm{RN}$-to-BSN class reflected on their confidence in the ability to search for, evaluate, and get articles at the end of their first course in week 14 and discussed whether it had increased since the end of their week 2 library assignment. All the students 
agreed that their confidence increased, but that they still needed more practice. One student commented, "I have been using library search skills quite a bit throughout the course for discussions, responses, the group teaching project, community and family assessments, and other projects. I feel that my confidence in my abilities to search for credible/ peer-reviewed articles has increased." As mentioned in the literature, finding the right keywords was the most frustrating step for many students. Continuing these reflections in more advanced classes would allow the librarian and nursing faculty to monitor the development and retention of the students' information literacy skills throughout the program.

\section{Summary}

The collaboration between a nurse educator and a librarian made it possible to incorporate the information literacy process into the nursing course outcomes of the first class in this RN-toBSN program. The reflections of students in this class suggest that becoming information literate fostered confidence in their ability to search for, find, and get scholarly information. These results have led other nursing faculty to include the librarian and the library research guide link in their classes. Continuing to expand the collaboration to other faculty and incorporating information literacy learning outcomes into more classes in the program could reinforce student confidence in integrating scholarly literature into their nursing practice.

\section{REFERENCES}

American Association of Colleges of Nursing (AACN). (2008). The essentials of baccalaureate education for professional nursing practice. Retrieved from http://www.aacn.nche.edu/publications/order-form/baccalaureate-essentials American Association of Colleges of Nursing. (2012, October 24). The impact of education on 
nursing practice (Fact Sheet). Retrieved from http://www.aacn.nche.edu/mediarelations/fact-sheets/impact-of-education

Argüelles, C. (2012). Program-integrated information literacy (PIIL) in a hospital's nursing department: A practical model. Journal of Hospital Librarianship, 12(2), 97-111. doi:10.1080/15323269.2012.665717

Association of College \& Research Libraries (ACRL). (2000). Information literacy competency standards for higher education. Retrieved March 29, 2013, from http://www.ala.org/acrl/standards/informationliteracycompetency

Connaway, L. S., Dickey, T. J., \& Radford, M. L. (2011). "If it is too inconvenient I'm not going after it:" Convenience as a critical factor in information-seeking behaviors. Library \& Information Science Research, 33(3), 179-190.

Diekema, A. R., Holliday, W., \& Leary, H. (2011). Re-framing information literacy: Problembased learning as informed learning. Library \& Information Science Research, 33(4), 261-268. doi:10.1016/j.lisr.2011.02.002

Duncan, V., \& Holtslander, L. (2012). Utilizing grounded theory to explore the informationseeking behavior of senior nursing students. Journal of the Medical Library Association, 100(1), 20-27. doi:10.3163/1536-5050.100.1.005

Flood, L., Gasiewicz, N., \& Delpier, T. (2010). Integrating information literacy across a BSN curriculum. Journal of Nursing Education, 49(2), 101-104. doi:10.3928/0148483420091023-01

Fox, B. E., \& Doherty, J. J. (2012). Design to learn, learn to design: Using backward design for information literacy instruction. Communications in Information Literacy, 5(2), 144-155. doi:10.7548/cil.v5i2.163 
Hickey, M. T., Forbes, M., \& Greenfield, S. (2010). Integrating the Institute of Medicine competencies in a Baccalaureate curricular revision: Process and strategies. Journal of Professional Nursing, 26(4), 214-222. doi:10.1016/j.profnurs.2010.03.001

Institute of Medicine. (2010). The future of nursing: Focus on education. Retrieved from http://www.iom.edu/Reports/2010/The-Future-of-Nursing-Leading-Change-AdvancingHealth/Report-Brief-Education.aspx

Kimok, D., \& Heller-Ross, H. (2008). Visual tutorials for point-of-need instruction in online courses. Journal of Library Administration, 48(3-4), 527-543. doi:10.1080/01930820802289656

Kvenild, C., \& Calkins, K. (2011). Embedded librarians: Moving beyond one-shot instruction. Chicago: Association of College and Research Libraries.

Miller, L., Jones, B., Graves, R., \& Sievert, M. (2010). Merging silos: collaborating for information literacy. Journal Of Continuing Education In Nursing, 41(6), 267-272. doi:10.3928/00220124-20100401-03

National Science Foundation. (2013, February 22). National Science Foundation collaborates with federal partners to plan for comprehensive public access to research results. National Science Foundation (NSF) News. Retrieved from http://www.nsf.gov/news/news_summ.jsp?cntn_id=127043

O'Keeffe, J., Willinsky, J., \& Maggio, L. (2011). Public access and use of health research: An exploratory study of the National Institutes of Health (NIH) Public Access Policy using interviews and surveys of health personnel. Journal of Medical Internet Research, 13(4), e97-e97.

Oakleaf, M. (2010). Writing information literacy assessment plans: A guide to best practice. 
Communications in Information Literacy, 3(2), 80-90. doi:10.7548/cil.v3i2.100

Pravikoff, D., Tanner, A., \& Pierce, S. (2005). Readiness of U.S. nurses for evidence-based practice: Many don't understand or value research and have had little or no training to help them find evidence on which to base their practice. American Journal of Nursing, 105(9), 40-52.

Reeb, B., \& Gibbons, S. (2004). Students, librarians, and subject guides: Improving a poor rate of return. portal: Libraries and the Academy, 4(1), 123-130.

Ryan, M., \& Ryan, M. (2013). Theorising a model for teaching and assessing reflective learning in higher education. Higher Education Research \& Development, 32(2), 244-257. doi:10.1080/07294360.2012.661704

Schulte, S. J., \& Sherwill-Navarro, P. J. (2009). Nursing educators' perceptions of collaboration with librarians. Journal of the Medical Library Association: JMLA, 97(1), 57-60. doi:10.3163/1536-5050.97.1.013

Schutt, M., \& Hightower, B. (2009). Enhancing RN-to-BSN students' information literacy skills through the use of instructional technology. Journal of Nursing Education, 48(2), 101105.

Slawson, D. C., \& Shaughnessy, A. (2005, July). Teaching evidence-based medicine: Should we be teaching information management instead? Academic Medicine, 80(7), 685-689. Retrieved from http://journals.lww.com/academicmedicine/Fulltext/2005/07000/Teaching_Evidence_Bas ed_Medicine_Should_We_Be.14.aspx

Solomons, N., \& Spross, J. (2011). Evidence-based practice barriers and facilitators from a continuous quality improvement perspective: an integrative review. Journal of Nursing 
Management, 19(1), 109-120. doi:10.1111/j.1365-2834.2010.01144.x

Sullo, E., Harrod, T., Butera, G., \& Gomes, A. (2012). Rethinking library service to distance education students: Analyzing the embedded librarian model. Medical Reference Services Quarterly, 31(1), 25-33. doi:10.1080/02763869.2012.641822

Suskie, L. A. (2010). Assessing student learning: a common sense guide (2nd ed.). San Francisco, CA: Jossey-Bass.

Turnbull, B., Royal, B., \& Purnell, M. (2011). Using an interdisciplinary partnership to develop nursing students' information literacy skills: An evaluation. Contemporary Nurse: A Journal for the Australian Nursing Profession, 38(1/2), 122-129.

\section{key points}

1. There are increased demands for BSN nurses to be actively involved in assessing and improving nursing practice based on evidence.

2. Information literacy is a process that can be actively learned and reinforced in an online environment in order for it to become a part of nursing practice.

3. Collaborations between nursing educators and librarians take advantage of the strengths of each discipline to integrate information literacy into continuing education online nursing course outcomes to foster students' confidence in finding current scholarly evidence to bring to their nursing practice. 